\title{
Transvaginal Sonographic Assessment Following Cervical Pessary Placement for Preterm Birth Prevention
}

\author{
William Schnettler, MD ${ }^{1,2}$ Shwetha Manoharan, $\mathrm{DO}^{1}$ Kate Smith, MD, PhD ${ }^{1,2}$ \\ ${ }^{1}$ Department of Obstetrics and Gynecology, TriHealth-Good \\ Samaritan Hospital, Cincinnati, Ohio \\ 2 Division of Maternal-Fetal Medicine, TriHealth-Good Samaritan \\ Hospital, Cincinnati, Ohio \\ Address for correspondence William T. Schnettler, MD, Seton Center \\ for Advanced Obstetrics, Good Samaritan Hospital, 375 Dixmyth \\ Avenue, Cincinnati, $\mathrm{OH} 45220$ \\ (e-mail:William_Schnettler@trihealth.com).
}

AJP Rep 2022;12:e80-e88.

\section{Abstract \\ Keywords \\ - preterm birth \\ - cervical pessary \\ - uterocervical angle \\ - intracervical angle \\ - cervical length \\ - funneling \\ - sonography \\ - ultrasound}

Background Transvaginal sonographic cervical length assessment identifies pregnant women at risk for preterm birth, and the subsequent placement of a cervical pessary may reduce this risk. The mechanism of action remains uncertain, and postplacement transvaginal sonography may provide further insight into the controversial efficacy of this therapy.

Objective To identify any pre- or postplacement sonographic findings associated with preterm delivery following cervical pessary insertion among at-risk women.

Materials and Methods This retrospective cohort study utilized electronic medical record and imaging review of all women identified within a large tertiary care health system having undergone cervical pessary placement for preterm birth risk reduction and subsequently delivered between January 2013 (the adoption of this therapeutic option in our system) and March 2017. Indications for cervical pessary placement were guided by maternal-fetal medicine consultation and required a functional cervical length measurement on transvaginal sonography of $25 \mathrm{~mm}$ or less. Criteria for initial transvaginal cervical assessment included obstetric history, multiple gestation, and current concern on transabdominal imaging for cervical shortening. All pre- and postplacement transvaginal sonographic measurements were determined for study purposes by re-review of each patient's images by a single author blinded to outcome. Results A total of 88 women were identified as having undergone cervical pessary placement for preterm birth prevention, and 52 yielded complete delivery and imaging data for inclusion. As expected, this was a high-risk population with $51.9 \%$ carrying multiple gestations, $32.7 \%$ with a history of prior preterm birth, and $11.6 \%$ with a history of cervical conization. Although previously hypothesized to represent the mechanism of action, neither the change in uterocervical or intracervical angle was associated with gestational age at delivery. Alternatively, preplacement imaging measurements of cervical funneling, anterior cervical length, and cervical diameter were significantly associated with appropriate pessary placement and decreased received

July 9,2020

accepted after revision

October 8, 2021
DOI https://doi.org/

10.1055/s-0041-1742273. ISSN 2157-6998.

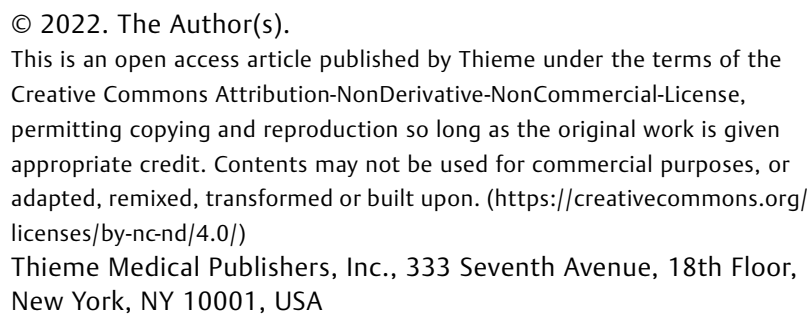


preterm birth. Forty-two subjects (80.8\%) demonstrated both the anterior and posterior aspects of the cervix within the pessary (appropriate placement) and $95.2 \%$ of these subjects demonstrated cervical funneling on initial imaging compared with $25 \%$ of those with inappropriate placement $(p=0.002)$. Anterior cervical length less than $20 \mathrm{~mm}$ and cervical diameter less than $33 \mathrm{~mm}$ were associated with preterm delivery less than 28 weeks ( 16.7 vs. $0 \%, p=0.039$ ), and anterior cervical length less than $20 \mathrm{~mm}$ was associated with preterm delivery less than 32 weeks ( 41.7 vs. $10.7 \%$, $p=0.025)$. Cervical diameter less than $33 \mathrm{~mm}$ correlated with an "inappropriately placed" pessary among $83.3 \%$ in comparison to $48.7 \%(p=0.048)$ of women with a cervical diameter less than $33 \mathrm{~mm}$. Significant associations were noted between postplacement functional cervical length measurements and preplacement anterior cervical length $(p=0.001)$ and cervical diameter $(p=0.012)$.

Conclusion Contrary to current thinking, no significant changes in uterocervical and intracervical angle following cervical pessary placement were identified. However, preplacement sonographic measurement of funneling, anterior cervical length, and cervical diameter are predictive of appropriate pessary placement and extreme preterm birth. These may represent markers for candidacy of cervical pessary placement. Postplacement transvaginal sonography represents an important tool to assess potential efficacy of this therapeutic modality, and further investigation of these factors is warranted.

Preterm birth represents the leading cause of neonatal morbidity and mortality and a significant burden on our health care system. ${ }^{1}$ Transvaginal sonography has revolutionized obstetric practice due to its superior performance among large prospective trials in determining preterm birth risk. $^{2-4}$ Asymptomatic women with cervical shortening (cervical length $\leq 25 \mathrm{~mm}$ ) are at increased risk for spontaneous preterm birth. ${ }^{2}$ Various treatments have been proposed and proven to reduce this risk, and recent evidence suggests that placement of a cervical pessary in pregnant women with cervical shortening may reduce the risk for spontaneous preterm delivery by more than $80 \%{ }^{5}$ However, controversy exists about the efficacy of this therapeutic option due to follow-up studies that failed to identify benefit. ${ }^{6,7}$ Perhaps the failure to demonstrate consistent efficacy involves the lack of clarity regarding the mechanism of action and appropriate measures of proper pessary placement. Investigations into the mechanism whereby cervical pessary placement may prevent preterm birth focus on the change in uterocervical angle. ${ }^{8-10}$ This concept was first introduced by Goya et al, and a follow-up study by Cannie et al utilized magnetic resonance imaging (MRI) to demonstrate that cervical pessary placement produced a more acute uterocervical angle correlating with a lower risk for preterm delivery prior to 34 weeks. ${ }^{8}$ However, the routine use of MRI to assess correct placement of the cervical pessary is neither practical nor cost-effective.

Transvaginal sonography offers a more practical and costeffective alternative. Although sonographic visualization of the cervix may be more difficult in the presence of a cervical pessary due to the "shadow" cast by the pessary, recent guidelines and techniques have been proposed to overcome this effect-reducing interobserver variability and supporting ultrasound's ability in assessing proper pessary placement. ${ }^{11}$ Recent investigations utilizing transvaginal sonography among patients at risk for preterm birth have demonstrated associations between various aspects of the uterocervical angle and both spontaneous preterm birth and cervical cerclage failure. ${ }^{9-13}$ This represents an active area of investigation, and many questions remain unanswered.

The purpose of this study was to investigate the potential mechanism of action and transvaginal sonographic markers associated with cervical pessary placement and preterm birth prevention. Specifically, we sought to investigate whether changes in uterocervical angle, intracervical angle, and other transvaginal sonographic measurements prior to and following cervical pessary placement were associated with preterm birth rates. We hypothesized that the change in uterocervical angle measured by transvaginal sonography immediately following cervical pessary placement results in a significant reduction in preterm delivery prior to 34.0 weeks' gestation. Furthermore, we hypothesized that additional sonographic measures exist for assessing appropriate candidacy and proper placement of cervical pessary placement for preterm birth reduction.

\section{Materials and Methods}

This retrospective cohort study utilized electronic medical record and imaging review of all women identified within a large tertiary care health system having undergone cervical pessary placement for preterm birth risk reduction between 


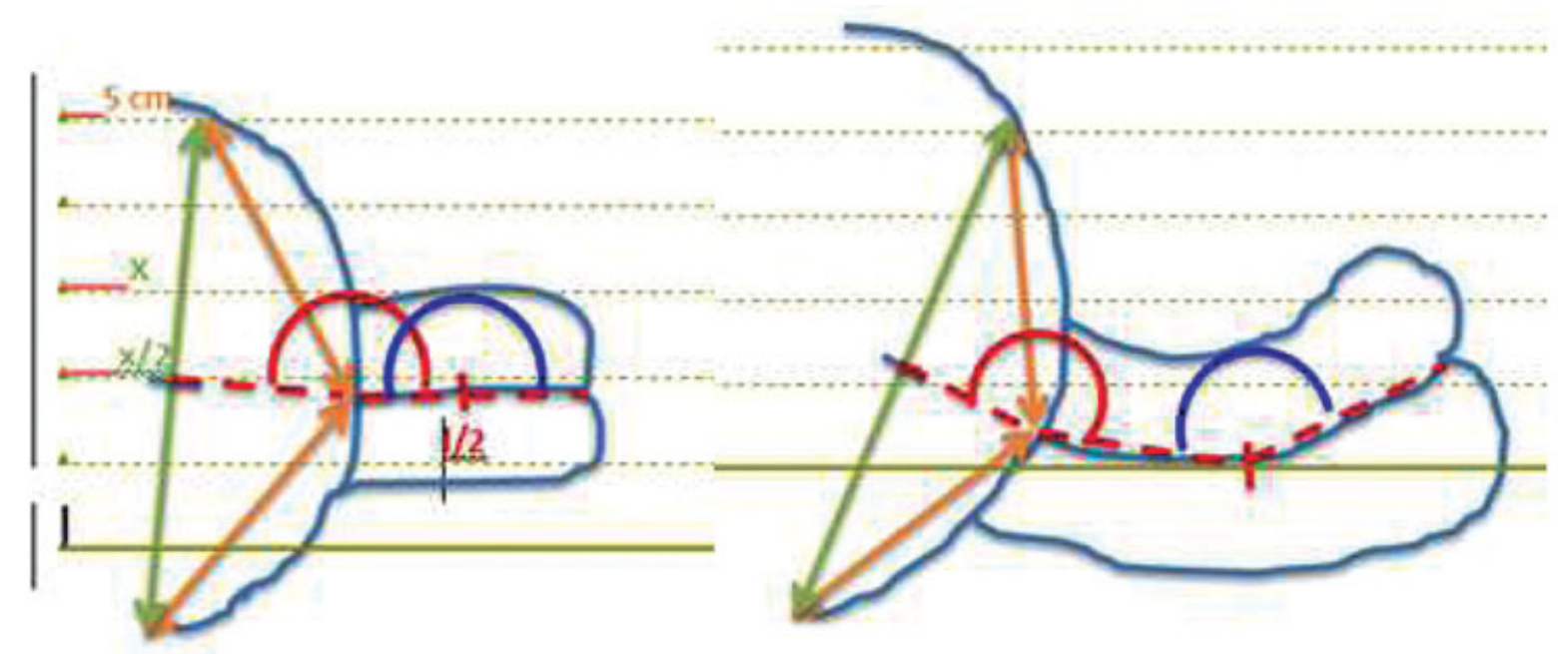

Fig. 1 Schematic of the measurement technique and hypothesized change in uterocervical and intracervical angle with cervical pessary placement.

January 2013 (the adoption of this therapeutic option in our system) and March 2017. This was a sample of convenience, and only women with complete obstetric and imaging data available for review were included in the analysis. Exclusion criteria included major fetal anomalies and the presence of a cervical cerclage. Participants were identified by queries of hospital billing data, electronic medical records, and imaging software (R4 ACERT Perinatal Reporting System; Hyland Software; Westlake, $\mathrm{OH}$ ). Indications for cervical pessary placement were guided by maternal-fetal medicine consultation and required a functional cervical length measurement on transvaginal sonography of $25 \mathrm{~mm}$ or less. Criteria for initial transvaginal cervical assessment included obstetric history, uterine anomalies, multiple gestation, and current concern on transabdominal imaging for cervical shortening. Although the performance of pre- and postplacement transvaginal sonographic measurements was not undertaken within a strict prospective research protocol, our practice involves routine follow-up transvaginal sonographic assessments within 1 week following introduction of a therapeutic modality to assess efficacy. This occurs whether the chosen therapeutic modality involves initiation of vaginal progesterone, cervical pessary placement, or cervical cerclage placement. All pre- and postplacement transvaginal sonographic measurements were determined for study purposes by re-review of each patient's images by a single author blinded to outcome (W.S.). All transvaginal images from the most-proximate examinations preceding and following cervical pessary placement were reviewed and used in determining eligibility and analysis.

The predetermined sonographic variables of interest included: uterocervical angle, intracervical angle, total cervical length (the sum of the closed cervical length and funnel length), straight "closed" cervical length, curved "closed" cervical length, funnel presence, funnel width, funnel length, anterior cervical length, cervical diameter, cervical edema, pessary height, and pessary "fit." Pessary fit was defined as greater than or equal to $5 \mathrm{~mm}$ difference between the cervi- cal diameter and pessary size. Cervical length measurements were performed utilizing the approach delineated by Iams et al. $^{2}$ We provide novel methodologies for the remaining calculations as described later. All measurements were performed utilizing the "postprocessing" measurement function within the imaging software. -Fig. 1 represents a schematic of the technique utilized to measure the uterocervical and intracervical angles. The uterocervical angle was calculated by first determining the vector of force upon the internal cervical os by the amniotic cavity. Equidistant straight-line measurements were extrapolated to the anterior and posterior uterine walls. A straight-line measurement was made between these two points, and the midpoint of that straight-line measurement was denoted. A straight line was then drawn between that point and the internal os. In the presence of a cervical funnel, the mid-point of the funnel width at the level of the cervicoisthmic junction was used to denote the "true" internal os. Next, the midpoint of the total cervical length was marked, and a straight line was drawn between this and the internal os. The angle between these vectors was then calculated as the uterocervical angle. The intracervical angle was calculated by measuring the angle between the proximal one-half cervical
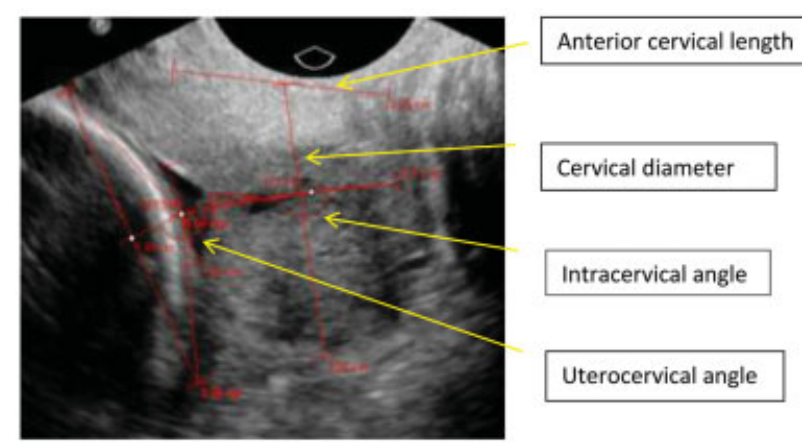

Fig. 2 Transvaginal sonographic example of uterocervical, intracervical angle, anterior cervical length, and cervical diameter measurements. 

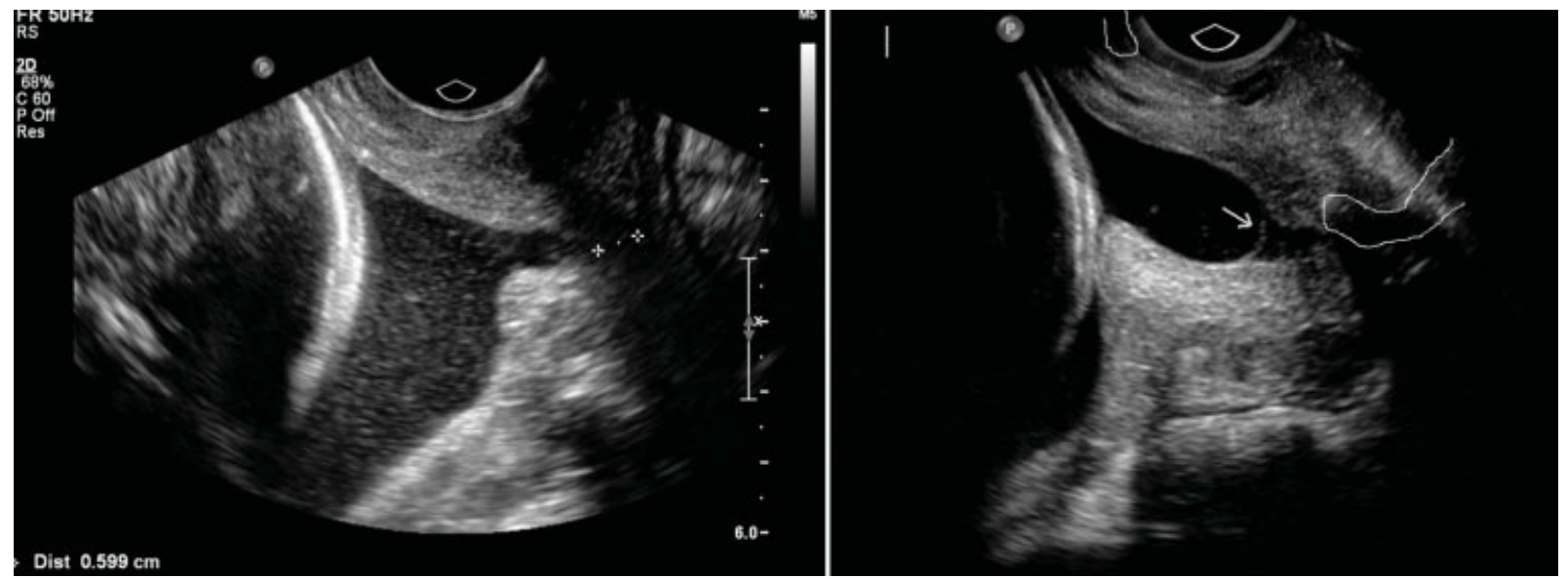

Fig. 3 Transvaginal sonographic examples of pessary "fit." Image on the left demonstrates appropriate fit with echolucent shadows from the anterior and posterior aspects of the pessary completely encircling the cervix. Image on the right demonstrates inappropriate pessary "fit" with the pessary aspects traced to illustrate how the posterior portion is sitting in the external cervical os.

length line and the distal one-half cervical length line. -Fig. 2 represents a transvaginal sonographic example of these calculations.

The anterior cervical length was measured by drawing a straight line between the distal point along the anterior cervical lip at the level of the external os and the caudalmost point of the echogenic bladder wall. Although unproven, these points were chosen due to their ease in identification and likelihood for interobserver consistency. The cervical diameter was determined by straight-line measurement between the anterior-most and posterior-most portions of the cervix at the proximal-most point of closed cervical length. This point was chosen to reflect the "width" of cervix able to be incorporated into the inner pessary diameter and to determine appropriateness in pessary "fit."

Determination of pessary "fit," or appropriate pessary placement, was based on whether both the anterior and posterior aspects of the cervix were encircled by the inner pessary diameter on postplacement imaging. Pessary fit was further defined as whether there was less than or equal to $5 \mathrm{~mm}$ difference between the measured cervical diameter and internal pessary diameter. - Fig. 3 illustrates sonographic images of one case with appropriate pessary "fit" and one case with inappropriate pessary placement. Pessary "height" among cases with appropriate pessary "fit" was determined by extrapolating a straight line between the medial portions of the inner pessary diameter and measuring the distance from where that line intersects the intracervical canal caudal to the external os as depicted in - Fig. 4.

Our primary outcome was preterm birth prior to 34.0 weeks' gestation. Additional outcomes included preterm birth prior to 28,32 , and 37 weeks. An initial sample size and power calculation were performed based on assumptions from the study by Cannie et al where preterm birth less than 34.0 weeks occurred in $15 \%$ of "high-risk" patients after cervical pessary placement. Of those who experienced preterm birth less than 34 weeks' gestation, the median change in uterocervical angle was 9 degrees. Of those who delivered beyond 34.0 weeks' gestation, the median change in utero- cervical angle was 14 degrees. Based on this, we assumed that a change in uterocervical of less than 10 degrees would correlate with a $30 \%$ risk of preterm birth prior to 34.0 weeks and a uterocervical angle change of more than 10 degrees would correlate with an $8 \%$ risk of preterm birth less than 34.0 weeks' gestation. Assuming a two-tailed $\alpha$ level of 0.05 and a power of $80 \%, 102$ women would have been needed to prove these assumptions. Given the sample of convenience and relative novelty of this therapeutic option, this sample size could not be met.

Statistical analysis was performed utilizing IBM SPSS Statistic software (version 22; Armonk, NY). Continuous variables that were normally distributed were described as means and analyzed utilizing the Student's $t$-test. Continuous variables with significant deviations from the normal distribution were described as medians and analyzed using Mann-Whitney's $U$ tests. $p$-Values of less than 0.05 were considered statistically significant. Chi-square and/or Fischer's exact tests were used for dichotomous variables.

Univariate tests were performed to evaluate associations with delivery less than $37,34,32$, and 28 weeks. Multiple logistic regression analyses were performed to assess for potential confounders and to determine which variables

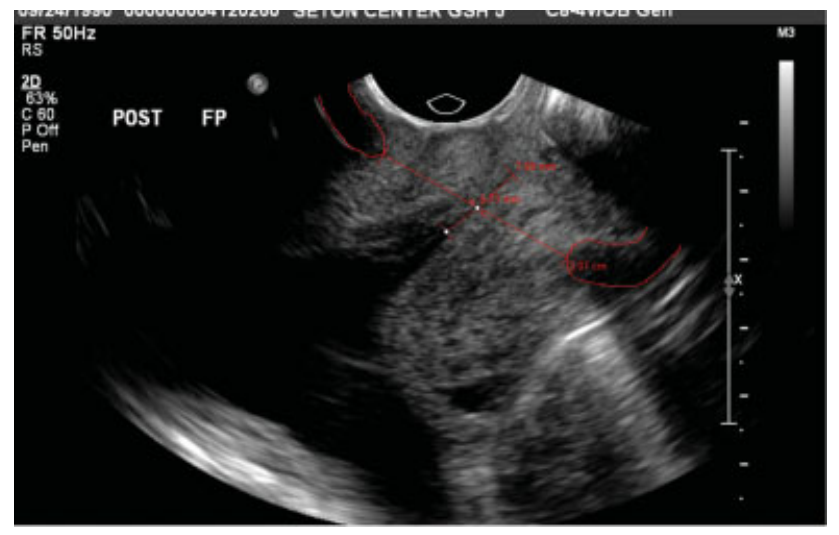

Fig. 4 Transvaginal sonographic image depicting pessary height determination. 
were significantly associated with outcomes. Additionally, we analyzed the dichotomous variables of anterior cervical length less than $20 \mathrm{~mm}$ and cervical diameter less than $33 \mathrm{~mm}$ with respect to pessary "fit" utilizing chi-square and Fisher's exact test.

\section{Results}

Eighty-eight women underwent cervical pessary placement for preterm birth prevention within our system over the course of the study period. Thirty-six were excluded from analysis due to the presence of a cervical cerclage in place (7), lack of complete obstetric and delivery data (17), and lack of complete imaging data (12). This allowed for complete analysis of 52 remaining women.

Descriptive characteristics of the 52 women are shown in -Table 1, and no significant associations with any of the outcomes were identified. As expected, this was a high-risk population with $51.9 \%$ carrying multiple gestations, $32.7 \%$ with a history of prior preterm birth, and $11.6 \%$ with a history of cervical conization. Preplacement sonographic determinations of cervical measurements also illustrate the high-risk nature of this population. As shown in -Table 2, the mean straight cervical length was $17.3 \mathrm{~mm}$ (standard deviation $[\mathrm{SD}] \pm 7.1$ ), and $86.5 \%$ of the women demonstrated some degree of cervical funneling. Despite the pessary placement, the mean gestational age at delivery for all women was 34.2 weeks, 23 (44.2\%) delivered prior to 34.0 weeks, and 33 (63.5\%) delivered preterm $(<37.0$ weeks). The mean latency from pessary placement to deliv-

Table 1 Descriptive characteristics for all subjects

\begin{tabular}{|l|l|}
\hline Descriptive & $\begin{array}{l}\text { Overall subjects } \\
(\boldsymbol{n}=52)\end{array}$ \\
\hline Maternal age & $28.7(5.0)$ \\
\hline Primiparous & $21(40.4 \%)$ \\
\hline Multiparous & $31(59.6 \%)$ \\
\hline Singleton gestation & $25(48.1 \%)$ \\
\hline Multiple gestation & $27(51.9 \%)$ \\
\hline Twin gestation & $21(40.3 \%)$ \\
\hline Triplet gestation & $6(11.5 \%)$ \\
\hline History of preterm delivery & $17(32.7 \%)$ \\
\hline History of cone bx & $6(12.0 \%)$ \\
\hline GA at delivery (mean) & $34.3(4.7)$ \\
\hline Delivery for PTL/PPROM & $33(63.4 \%)$ \\
\hline Latency $<6$ wk & $11(21.2 \%)$ \\
\hline Latency $<8$ wk & $13(25.0 \%)$ \\
\hline Latency $<11$ wk & $23(44.2 \%)$ \\
\hline Mean latency (wk) & $11.1(4.6)$ \\
\hline
\end{tabular}

Abbreviations: GA, gestational age; PPROM, preterm premature rupture of the membranes; PTL, preterm labor.

Note: Data are reported as mean ( \pm standard deviation) or $n(\%)$ unless otherwise specified. ery was 11 weeks, and 10 (19.2\%) women only achieved a latency of 5 weeks or less.

Regarding the primary outcome, no association was identified between the change in uterocervical angle and delivery prior to 34 weeks. As shown in - Table 3, no associations were identified for either the change in uterocervical angle or intracervical angle and extremely preterm birth (prior to 28 weeks). None of the standard cervical measurements routinely employed in current clinical practice was associated with gestational at delivery. Interestingly, postplacement imaging identified 10 women (19.2\%) where the pessary was not encircling the cervix. One can assume that the pessary is not likely functioning to prevent preterm birth in this circumstance. Comparisons between these women and the remaining 42 with the pessary encircling the cervix identified no significant differences in mean gestational age at delivery ( 32.4 vs. 34.6 weeks; $p=0.18$ ). Although not statistically significant, $20 \%$ of women delivering prior to 28 weeks did not have the entire cervix encircled within the pessary as compared with $4.8 \%$ of patients with complete encircling of the cervix by the pessary. The mean postplacement straight cervical length measurements were $6 \mathrm{~mm}$ longer among those with the pessary in place versus those with the pessary not in place ( 19.6 vs. $13.9 \mathrm{~mm} ; p=0.7$ ). The funnel width was wider among those with the pessary in place (13.1 vs. $7.4 \mathrm{~mm} ; p=0.029$ ) (-Table 4). However, the postplacement funnel width measurements were not different between those with and without the cervix within the

Table 2 Cervical measurements of all subjects pre-and postpessary placement, as well as the differences in measurements following placement

\begin{tabular}{|c|c|c|c|}
\hline $\begin{array}{l}\text { Cervical } \\
\text { measurements } \\
(n=52)\end{array}$ & Prepessary & Postpessary & Delta \\
\hline $\begin{array}{l}\text { Total cervical length } \\
(\mathrm{mm})\end{array}$ & $32.5(9.5)$ & & \\
\hline $\begin{array}{l}\text { Straight cervical length } \\
\text { (funnel length) (mm) }\end{array}$ & $17.2(7.2)$ & $18.2(11.6)$ & $0.90(12.3)$ \\
\hline $\begin{array}{l}\text { Curved cervical length } \\
(\mathrm{mm})\end{array}$ & $17.7(7.5)$ & $18.6(12.1)$ & $0.94(12.8)$ \\
\hline Intracervical angle (deg) & $163.5(19.3)$ & $172.7(19.7)$ & $3.0(-53,125)$ \\
\hline Uterocervical angle (deg) & $188.0(20.6)$ & $188.8(27.6)$ & $4.0(-106,48)$ \\
\hline Funnel width (mm) & $11.9(7.5)$ & $10.0(0,38)$ & $-2.0(-23,38)$ \\
\hline Funnel length (mm) & $13.0(0,52)$ & $14.00(0,52)$ & $-0.94(11.0)$ \\
\hline $\begin{array}{l}\text { Anterior cervical length } \\
(\mathrm{mm})\end{array}$ & $20.5(4.8)$ & & \\
\hline Cervical diameter (mm) & $36.7(5.8)$ & & \\
\hline Pessary height (mm) & & $10.6(7.1)$ & \\
\hline $\begin{array}{l}\text { GA at pessary placement } \\
(w k)\end{array}$ & $23.2(2.4)$ & & \\
\hline Funnel present & 45 (86.5\%) & 39 (75.0\%) & \\
\hline Anterior $\mathrm{CL}<20 \mathrm{~mm}$ & $24(46.2 \%)$ & & \\
\hline $\begin{array}{l}\text { Cervical } \\
\text { diameter }<33 \mathrm{~mm}\end{array}$ & $12(23.1 \%)$ & & \\
\hline
\end{tabular}

Abbreviations: $\mathrm{CL}$, cervical length; $\mathrm{GA}$, gestational age.

Note: Data are reported as mean ( \pm standard deviation), median (range, minimum, maximum), or $n(\%)$ unless otherwise specified. 
Table 3 The standard cervical measurements of the subjects who delivered prior to 28 weeks, pre- and postpessary placement, as well as the change in the cervical measurements after pessary placement (i.e., the delta difference) as compared with the subjects that delivered $\geq 28$ weeks

\begin{tabular}{|c|c|c|c|c|c|c|c|c|c|}
\hline \multirow[t]{2}{*}{ Measurement } & \multicolumn{3}{|c|}{ Initial measurements } & \multicolumn{3}{|c|}{ Postpessary measurements } & \multicolumn{3}{|c|}{ Delta measurements } \\
\hline & $\begin{array}{l}\text { Delivery } \\
<28\end{array}$ & $\begin{array}{l}\text { Delivery } \\
\geq 28\end{array}$ & $p$-Value & $\begin{array}{l}\text { Delivery } \\
<28\end{array}$ & $\begin{array}{l}\text { Delivery } \\
\geq 28\end{array}$ & $p$-Value & $\begin{array}{l}\text { Delivery } \\
<28\end{array}$ & $\begin{array}{l}\text { Delivery } \\
\geq 28\end{array}$ & $p$-Value \\
\hline $\begin{array}{l}\text { Total cervical length } \\
(\mathrm{mm})\end{array}$ & $31.5(14.9)$ & $32.7(9.1)$ & 0.809 & & & & & & \\
\hline $\begin{array}{l}\text { Straight cervical } \\
\text { length }(\mathrm{mm})\end{array}$ & $14.5(10.6)$ & $17.5(6.8)$ & 0.417 & $15.5(18.4)$ & $18.8(11.3)$ & 0.601 & $1(18.4)$ & $1.2(11.9)$ & 0.974 \\
\hline $\begin{array}{l}\text { Curved cervical } \\
\text { length }(\mathrm{mm})\end{array}$ & $15.0(11.2)$ & $18.0(7.2)$ & 0.447 & $16.3(19.5)$ & $19.2(11.8)$ & 0.783 & $1.3(20.0)$ & $1.23(12.4)$ & 0.998 \\
\hline $\begin{array}{l}\text { Intracervical angle } \\
\text { (deg) }\end{array}$ & $162.5(20.6)$ & $163.5(19.2)$ & 0.918 & $161.8(21.4)$ & $174.1(19.6)$ & 0.236 & $13.5(76)$ & $10.5(28.3)$ & 0.456 \\
\hline $\begin{array}{l}\text { Uterocervical angle } \\
\text { (deg) }\end{array}$ & $195.5(18.5)$ & $188.0(21.1)$ & 0.496 & $198.3(14.6)$ & $188.1(28.1)$ & 0.481 & $6.0(-17,16)$ & $3.0(-106,48)$ & 0.908 \\
\hline Funnel width (mm) & $11.2(9.2)$ & $12.0(7.4)$ & 0.844 & $10.5(0,38)$ & $10.0(0,27)$ & 0.908 & $7.0(-10,38)$ & $0.0(-23,25)$ & 0.679 \\
\hline Funnel length (mm) & $8.0(0,52)$ & $13.0(0,37)$ & 0.607 & $10.0(0,52)$ & $14.0(0,47)$ & 0.906 & $1.0(8.4)$ & $-1.5(11.4)$ & 0.674 \\
\hline $\begin{array}{l}\text { Anterior cervical } \\
\text { length (mm) }\end{array}$ & $16.7(3.9)$ & $20.9(4.7)$ & 0.093 & & & & & & \\
\hline
\end{tabular}

Notes: Data are reported as mean ( \pm standard deviation), median (range, minimum, maximum), or $n(\%)$ unless otherwise specified. Delivery $<28$ weeks' gestation or $\geq 28$ weeks' gestation.

pessary ( $p=0.725)$. The change in intracervical angle whether or not the pessary is in place differs by about only 10 degrees, and this is not significant. Similarly, the change in uterocervical angle does not seem to be statistically significant between the subjects who had their cervix within the pessary and those who did not. When analyzing only the 42 women with the cervix within the pessary, no association was identified between preterm birth outcomes.

Table 4 Comparing cervical measurements with subjects whose cervix was within the pessary versus those with the cervix not within the pessary

\begin{tabular}{|c|c|c|c|c|c|c|c|c|c|}
\hline \multirow[t]{2}{*}{ Measurement } & \multicolumn{3}{|c|}{ Initial measurements } & \multicolumn{3}{|c|}{ Postpessary measurements } & \multicolumn{3}{|c|}{ Delta measurements } \\
\hline & $\begin{array}{l}\text { Cervix } \\
\text { within }\end{array}$ & $\begin{array}{l}\text { Cervix } \\
\text { not within }\end{array}$ & $p$-Value & $\begin{array}{l}\text { Cervix } \\
\text { within }\end{array}$ & $\begin{array}{l}\text { Cervix } \\
\text { not within }\end{array}$ & $p$-Value & $\begin{array}{l}\text { Cervix } \\
\text { within }\end{array}$ & $\begin{array}{l}\text { Cervix } \\
\text { not within }\end{array}$ & $p$-Value \\
\hline $\begin{array}{l}\text { Total cervical length } \\
(\mathrm{mm})\end{array}$ & $32.43(8.5)$ & $33.4(13.2)$ & 0.829 & & & & & & \\
\hline $\begin{array}{l}\text { Straight cervical } \\
\text { length }(\mathrm{mm})\end{array}$ & $17.1(6.7)$ & $18.1(9.0)$ & 0.699 & $19.6(11.9)$ & $13.9(10.3)$ & 0.171 & $2.5(12.6)$ & $-4.2(9.8)$ & 0.125 \\
\hline $\begin{array}{l}\text { Curved cervical } \\
\text { length }(\mathrm{mm})\end{array}$ & $17.4(7.0)$ & $19.0(9.5)$ & 0.560 & $20.1(12.5)$ & $14.2(10.6)$ & 0.173 & $2.7(13.1)$ & $-4.8(9.9)$ & 0.098 \\
\hline $\begin{array}{l}\text { Intracervical angle } \\
\text { (deg) }\end{array}$ & $165.7(18.4)$ & $154.1(20.0)$ & 0.085 & $175.1(19.9)$ & $164.6(17.9)$ & 0.131 & $2.5(-53,125)$ & $9.5(-12,42)$ & 0.919 \\
\hline $\begin{array}{l}\text { Uterocervical angle } \\
\text { (deg) }\end{array}$ & $187.9(21.1)$ & $191.3(20.5)$ & 0.652 & $185.9(29.0)$ & $201.1(14.4)$ & 0.117 & $3(-106,48)$ & $10.5(-10,40)$ & 0.245 \\
\hline Funnel present & $40 / 42$ (95.2\%) & $5 / 10(50.0 \%)$ & 0.002 & $32 / 42(76.1 \%)$ & $7 / 10(70.0 \%)$ & 0.685 & & & \\
\hline $\begin{array}{l}\text { Funnel width } \\
(\mathrm{mm})\end{array}$ & $13.0(6.8)$ & $7.4(8.6)$ & 0.029 & $10(0,27)$ & $15(0,38)$ & 0.779 & $4.0(-23,25)$ & $0.5(-11,38)$ & 0.092 \\
\hline $\begin{array}{l}\text { Funnel length } \\
(\mathrm{mm})\end{array}$ & $13(0,37)$ & $8(0,52)$ & 0.650 & $14(0,47)$ & $14.5(0,52)$ & 0.857 & 1.4 (11.9) & $-0.9(8.1)$ & 0.904 \\
\hline $\begin{array}{l}\text { Anterior cervical } \\
\text { length }(\mathrm{mm})\end{array}$ & $20.9(4.6)$ & $19.6(5.6)$ & 0.460 & & & & & & \\
\hline Cervical diameter & $37.1(5.8)$ & $35.1(5.9)$ & 0.320 & & & & & & \\
\hline Pessary height & & & & $12.9(5.8)$ & $1.1(3.4)$ & $<0.001$ & & & \\
\hline
\end{tabular}

Note: Data are reported as mean ( \pm standard deviation), median (range, minimum, maximum), or $n(\%)$ unless otherwise specified. Values in bold represent statistical significance $(p<0.05)$. 
Table 5 Dichotomous variables of anterior length less than $20 \mathrm{~mm}$ and cervical diameter less than $33 \mathrm{~mm}$ with respect to gestational age at delivery

\begin{tabular}{|c|c|c|c|c|c|c|}
\hline Delivery timing & $\begin{array}{l}\text { Anterior } \\
\mathrm{CL}<20 \mathrm{~mm} \\
(n=24)\end{array}$ & $\begin{array}{l}\text { Anterior } \\
\mathrm{CL} \geq 20 \mathrm{~mm} \\
(n=28)\end{array}$ & $p$-Value & $\begin{array}{l}\text { CD } \\
<33 \mathrm{~mm} \\
(n=12)\end{array}$ & $\begin{array}{l}\mathrm{CD} \\
\geq 33 \mathrm{~mm} \\
(n=40)\end{array}$ & $p$-Value \\
\hline Delivery $<28$ wk & $4(16.7 \%)$ & $0(0 \%)$ & 0.039 & $3(25.0 \%)$ & $1(2.5 \%)$ & 0.034 \\
\hline Delivery $<32$ wk & $10(41.7 \%)$ & $3(10.7 \%)$ & 0.025 & $3(25.0 \%)$ & $10(25.0 \%)$ & 1.00 \\
\hline Delivery $<34 \mathrm{wk}$ & $15(62.5 \%)$ & $8(28.6 \%)$ & 0.030 & $5(41.7 \%)$ & $18(45.0 \%)$ & 1.00 \\
\hline Delivery $<37$ wk & $17(70.8 \%)$ & $16(57.1 \%)$ & 0.463 & $7(58.3 \%)$ & $26(65.0 \%)$ & 0.739 \\
\hline
\end{tabular}

Abbreviations: $\mathrm{CD}$, cervical diameter; $\mathrm{CL}$, cervical length.

Note: Data are $n(\%)$ unless otherwise specified.

Interesting associations were identified between several of the novel cervical measurements and preterm birth outcomes. Anterior cervical length less than $20 \mathrm{~mm}$ and cervical diameter less than $33 \mathrm{~mm}$ were significantly associated with preterm delivery less than 28 weeks, and anterior cervical length less than $20 \mathrm{~mm}$ was also significantly associated with preterm delivery less than 32 weeks (- Table 5). Interestingly, a longer anterior cervical length was also significantly associated a greater straight cervical length measurement following pessary placement $(p=0.001)$. The association of anterior cervical length less than $20 \mathrm{~mm}$ and preterm birth prior to 28 weeks remained when analyzing only those with the pessary completely encircling the cervix $(p=0.039)$. An association was also found between the pessary height $(p=0.016)$ and cervical diameter less than $33 \mathrm{~mm}$ with delivery less than 28 weeks, but not with delivery less than 32,34 , or 37 weeks (-Table 6 ), and not associated with latency less than 6,8 , and 11 weeks (data not shown).
In looking at whether the appropriate size of pessary was placed, we compared women in whom the difference between the cervical diameter measurement and the internal pessary diameter was less than $5 \mathrm{~mm}$ with those with a difference more than $5 \mathrm{~mm}$. The mean difference between these two variables among the women was $0.7 \mathrm{~mm}( \pm \mathrm{SD} 6.5 \mathrm{~mm})$, and only $43.1 \%$ of the women had pessaries of appropriate size placed; $25.5 \%$ of the women had pessaries placed with an internal diameter more than $5 \mathrm{~mm}$ smaller than their cervical diameter measurements, and $31.4 \%$ had pessaries placed with an internal diameter more than $5 \mathrm{~mm}$ larger than their cervical diameter measurements. No associations were identified between the appropriateness of pessary size and preterm birth outcomes. Additionally, if the cervical diameter was greater than or equal to $33 \mathrm{~mm}$, then $51.3 \%$ of subjects had an appropriately sized pessary placed. In comparison, only $16.7 \%$ of subjects with a cervical diameter less than $33 \mathrm{~mm}$ had an appropriately sized pessary $(p=0.048)$. A larger

Table 6 Pessary height and cervix characteristics versus delivery timing of subjects of those with an appropriately placed pessary $(n=42)$

\begin{tabular}{|c|c|c|c|c|}
\hline Cervix characteristics & $\begin{array}{l}\text { Pessary height } \\
(\mathrm{mm})\end{array}$ & $\begin{array}{l}\text { Cervical diameter } \\
\text { (initial) }\end{array}$ & $\begin{array}{l}\text { Cervical edema } \\
(n=11)\end{array}$ & Anterior $\mathrm{CL}$ \\
\hline Delivery $<28$ wk & $22.5(3.5)$ & $27.5(4.6)$ & $1(50.0 \%)$ & $18.5(0.7)$ \\
\hline Delivery $\geq 28$ wk & $12.5(5.5)$ & $37.6(5.4)$ & $10(25.0 \%)$ & $21.0(4.7)$ \\
\hline$p$-Value & 0.015 & 0.013 & 0.460 & 0.465 \\
\hline Delivery $<32$ wk & $14.4(7.4)$ & $36.2(5.9)$ & $3(30.0 \%)$ & $19.5(5.8)$ \\
\hline Delivery $\geq 32$ wk & $12.5(5.3)$ & $37.4(5.8)$ & $8(25.0 \%)$ & $21.3(4.2)$ \\
\hline$p$-Value & 0.364 & 0.560 & 1.00 & 0.291 \\
\hline Delivery $<34$ wk & $13.6(6.6)$ & $36.4(4.7)$ & $5(29.4 \%)$ & $19.6(5.4)$ \\
\hline Delivery $\geq 34$ wk & $12.5(5.3)$ & $37.6(6.4)$ & $6(24.0 \%)$ & 21.7 (3.9) \\
\hline$p$-Value & 0.550 & 0.479 & 0.733 & 0.143 \\
\hline Delivery $<37$ wk & $13(6.6)$ & $37.6(5.1)$ & $8(32.0 \%)$ & $20.1(4.6)$ \\
\hline Delivery $\geq 37$ wk & $12.8(4.6)$ & $36.4(6.7)$ & $3(17.6 \%)$ & $22(4.5)$ \\
\hline$p$-Value & 0.924 & 0.504 & 0.477 & 0.188 \\
\hline
\end{tabular}

Abbreviation: $\mathrm{CL}$, cervical length.

Notes: Data reported as $n(\%)$ unless otherwise specified. Data are reported as mean ( \pm standard deviation). Subjects with good placement were defined as those with both anterior and posterior lips of their cervix within the pessary. Excluded subjects with cervix not well placed in pessary. 
cervical diameter was associated with a more appropriately sized pessary. None of the standard or angle measurements was associated with pessary fit except funnel width $(p=0.047)$. Of women with the pessary in place, $40 / 42$ (95.2\%) had funneling on initial cervical length, compared with only $5 / 20(25 \%)$ of those with the pessary not in place $(p=0.002)$.

\section{Discussion}

Our results suggest that the changes in uterocervical or intracervical angles do not substantiate the current theory regarding the mechanism of action of the cervical pessary in preterm birth prevention, and we identified several novel cervical measurements that may identify appropriate candidates in whom cervical pessary placement may prove efficacious. Additionally, we identified that postplacement transvaginal sonographic cervical assessment is a useful modality in providing optimal care to women undergoing this therapy in that 10 of 52 women (19.2\%) were found to have pessaries not encircling their cervices following placement. Although no statistically significant associations were proven between women with complete encircling of the cervix versus those without complete cervical encircling, the proportions delivering prior to 28 weeks may suggest a possible clinical significance ( 4.8 vs. $20 \%$ ). The novel measurements of anterior cervical length and cervical diameter demonstrated significant association with extreme preterm birth and appropriate pessary placement. It is interesting that within the women with the pessary in place, 40/42 (95.2\%) had funneling on initial cervical length, compared with only $25 \%$ of those with the pessary not in place $(p=0.002)$. Although not statistically significant, 10/42 (23.8\%) women experienced resolution of cervical funneling if the pessary was in place versus none if the pessary was not in place $(p=0.178)$, and the funnel width became smaller in $27 / 42(64.3 \%)$ of subjects whose pessary was in place in comparison to only $40 \%$ of women who did not have their pessary in place $(p=0.282)$. These findings suggest that women with a longer anterior cervical length $(>20 \mathrm{~mm})$, wider cervical diameter ( $>33 \mathrm{~mm}$ ), and funneling identified on transvaginal sonographic assessment may represent the candidates best suited for cervical pessary placement for extreme preterm birth prevention.

The merits of this study lie in the novel exploration of a myriad of sonographic cervical measurements among women undergoing cervical pessary placement for preterm birth prevention. All measurements were ascertained by a single investigator blinded to outcome. We propose several novel methodologies for further exploration, and we utilized a proven and standardized method of transvaginal sonographic imaging for women with a cervical pessary in place. This evaluation was also undertaken among women in whom several pessary size options were offered which differs somewhat from current consensus recommendations (a current Maternal-Fetal Medicine Units study, called the PROSPECT trial, in which a limited range of pessary sizes are offered based on parity). As we have shown, the option of differing pessary sizes may be clinically relevant in providing the most efficacy in preterm birth prevention. It is important to note the shortcomings of this study. Due to the sample of convenience, adequate power was not achieved to definitively explore the primary outcome. The original power calculation was based on data from the study by Cannie et al which included only singleton gestations in its analysis and thus largely differed from our more heterogenous population. Additionally, the retrospective ascertainment of the cervical measurements was dependent on the quality of imaging performed outside of a prospective research protocol. Thus, this initial report may leave readers with more questions than answers. Larger, prospective, and multicenter investigation is warranted in pursuit of identifying the true efficacy, mechanism of action, and appropriate patient selection for cervical pessary placement in preventing preterm birth.

\section{Conclusion}

In conclusion, the presumption that preterm birth prevention is achieved by changes in uterocervical angle or intracervical angle with cervical pessary placement may not be true. Alternatively, further exploration into the ability of transvaginal sonography to augment our ability to utilize a potential preterm birth preventative methodology such as the cervical pessary is worthy of further exploration.

\section{Condensation}

Pre- and postpessary placement sonographic characteristics can identify ideal candidates for pessary benefit and those at risk for extreme preterm birth.

\section{Authors' Contribution}

W.S. helped in conceptualization, writing-original draft, review, and editing, methodology, investigation, visualization, and supervision. K.S. helped in formal analysis, resources, and methodology. S.M. helped in conceptualization, writing-original draft, and investigation.

Conflict of Interest

None declared.

\section{References}

1 Committee on Understanding Premature Birth and Assuring Healthy Outcomes, Board on Health Sciences Policy. Preterm birth causes, consequences, and prevention. In: Berhman RE, Butler AS, eds. Institute of Medicine of the National Academies. Washington DC: The National Academies Press; 2007

2 Iams JD, Goldenberg RL, Meis PJ, et al; National Institute of Child Health and Human Development Maternal-Fetal Medicine Unit Network. The length of the cervix and the risk of spontaneous premature delivery. N Engl J Med 1996;334(09):567-572

3 Owen J, Yost N, Berghella V, et al; National Institute of Child Health and Human Development, Maternal-Fetal Medicine Units Network. Mid-trimester endovaginal sonography in women at high risk for spontaneous preterm birth. JAMA 2001;286(11): 1340-1348

4 Berghella V, Tolosa JE, Kuhlman K, Weiner S, Bolognese RJ, Wapner RJ. Cervical ultrasonography compared with manual examination 
e88 Sonographic Characteristics Identify Candidates for Pessary Schnettler et al.

as a predictor of preterm delivery. Am J Obstet Gynecol 1997;177 (04):723-730

5 Goya M, Pratcorona L, Merced C, et al; Pesario Cervical para Evitar Prematuridad (PECEP) Trial Group. Cervical pessary in pregnant women with a short cervix (PECEP): an open-label randomised controlled trial. Lancet 2012;379(9828):1800-1806

6 Abdel-Aleem H, Shaaban OM, Abdel-Aleem MA. Cervical pessary for preventing preterm birth. Cochrane Database Syst Rev 2013; (05):CD007873

7 Nicolaides KH, Syngelaki A, Poon LC, et al. Cervical pessary placement for prevention of preterm birth in unselected twin pregnancies: a randomized controlled trial. Am J Obstet Gynecol 2016;214(01):3.e1-3.e9

8 Cannie MM, Dobrescu O, Gucciardo L, et al. Arabin cervical pessary in women at high risk of preterm birth: a magnetic resonance imaging observational follow-up study. Ultrasound Obstet Gynecol 2013;42(04):426-433
9 Dziadosz M, Bennett TA, Dolin C, et al. Uterocervical angle: a novel ultrasound screening tool to predict spontaneous preterm birth. Am J Obstet Gynecol 2016;215(03):376.e1-376.e7

10 Knight JC, Tenbrink E, Sheng J, Patil AS. Anterior uterocervical angle measurement improves prediction of cerclage failure. J Perinatol 2017;37(04):375-379

11 Goya M, Pratcorona L, Higueras T, Perez-Hoyos S, Carreras E, Cabero L. Sonographic cervical length measurement in pregnant women with a cervical pessary. Ultrasound Obstet Gynecol 2011; 38(02):205-209

12 Thangatorai R, Lim FC, Nalliah S. Cervical pessary in the prevention of preterm births in multiple pregnancies with a short cervix: PRISMA compliant systematic review and meta-analysis. J Matern Fetal Neonatal Med 2018;31(12):1638-1645

13 Society for Maternal-Fetal Medicine (SMFM) Publications Committee. The role of cervical pessary placement to prevent preterm birth in clinical practice. Am J Obstet Gynecol 2017;216(03):B8-B10 